RÉSUMÉ

Étude de la biologie d'Aphidius rhopalosiphi (Hymenoptera: Aphidiidae), parasitoide de pucerons des céréales

Nous avons examiné quelques aspects des relations entre le parasitoide Aphidius rhopalosiphi et so hôte Sitobion avenae. La fécondité potentielle "réalisée": nombre de pucerons momifiés (212). La plupart des œufs étaient pondus dans la première semaine de la vie imaginale (fig. 1). Le super-parasitisme s'est produit dans les conditions expérimentales, mais la distribution des larves (fig. 2) s'écartait une certaine discrimination parmi les ce qui indiquait maximum de 23 jours. Le taux sexuel (fig. 3) pour l'ensemble de la descendance était $1 / 1$, mais changeait dans le temps. Après le premier jour de ponte, plus de femelles que de mâles étaient obtenues; mais après 6 jours, il n'y avait presque plus que

Le taux de rencontre des aphides et des paraside prospection de l'hôte était en moyenne de 2 se condes, mais dans certains cas il atteignait 10 secondes ou plus. La proportion de rencontres efficaces etait plus faible au 4 eme stade (fig. 4b). Il n'y avai ves. de parasitoïdes obtenues par rencontre de lafles stades 1 à 3 des pucerons, mais elle était significativement inférieure au 4ème stade par rapport au second. Les taux globaux de succès (taux de rencontre et nombre de larves formees par rencontre)

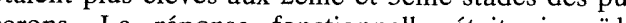

REFERENCES

Carter, N., McLean, I. F. G., Watt, A. D. \& Dixon, and review. Applied biology, 5: 271-348.

ansfield, R. D. (1979). Aspects of host-

interactions of two aphid parasitoids, Aphidiu urticae (Haliday) and Aphidius uzbekistanicus (Luzhetski) (Hymenoptera: Aphidiidae). Ecol. (197). A Stride

rland, K. D. \& George, K. S (19al). Studies on polyphagous preda

Hart, J., de Jonge, J., Colle, C., Dicke, M., van Lenteren, J. C. \& Ramakers, P. M. J. (1978) Host selection, host discrimination and functonal response of Aphidius matricariae (Haliday) green peach aphid, Myzus persicae (Sulz.). Med.
Fac. Landbouww. Rijksuniv. Gent 43: 441-453. (197) . S., Lawton, J. H. \& Beddington, J. R. brate predators and paraitoids. $J$.

Holling, C. S. (1959). The components of predation as revealed by a study of small mammal preda-
tion of the European Pine Sawfly. Can. Ent. 91: 293-320.

nes, M. G. (1972). Cereal aphids: their parasite and predators caught in cages over oat and winter wheat crops. Ann. appl. Biol. 72: 13-25. host discrimination and the prevention of superparasitism in the parasite Pseudeucoila boche (Hymenoptera: Cynipidae). Neth. J. Zool. 26

$1-83$.
Lenteren, J. C. van \& Bakker, K. (1976). Functional responses

MacKauer, M. \& van den Bosch, R. (1973). Genera D. 10:330-335.

cLean, I. F. G. (1980). Ecology of the Natura Enemies of Cereal Aphids. Unpubl. Ph. D. The

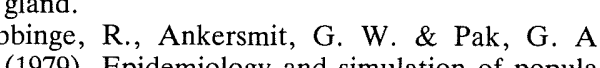
(1979). Epidemiology and simulation of populawheat. Neth. J. Pl. Path. 85: 197-220

Rautapää, J. (1972). The importance of Coccinell septempunctata L. (Coleoptera: Coccinellidae) in the yield and quality of barley. Ann. Agpic. Fen. 11: 424-436.

- (1975). Control of Rhopalosiphum padi (L.) (Homoptera: Aphididae) with Coccinella septem punctata (L.) (Coleoptera: Coccinellidae) in cages and effect of late aphid infestation on bar ley yild. Ann. Agric Fem 14:231-239.

Starý, P. (1962). Hymenopterous parasites of the pea aphid Acyrthosiphon onobrychis (Boyes) in
Czechoslovakia. I. Bionomics and ecology of Aphidius ervi (Haliday). Folia Zoologica, Brno, 11: 265-278.

(1972). Aphidius uzbekistanicus (Luzhetzki) Hymenoptera: Aphidiidae), a parasite of grami. and ecology of Aphidius smithi Sharma \& Subbe Rao (Hymenoptera: Braconidae), a parasite of the pea aphid Acyrthosiphon pisum (Harr.) Homoptera: Aphididae). Bull. Ent. Pologne 32:
253-310.

\section{BIOLOGY OF APHIDIUS RHOPALOSIPHI, A PARASITOID OF}

\section{CEREAL APHIDS}

Y. SHIROTA ${ }^{2,3}$ ), N. CARTER ${ }^{1,4}$ ), R. RABBINGE2 2 ) and G. W. ANKERSMIT1)

1,2) Departments of Entomology and of Theoretical Production Ecology, Agricultural University, Wageningen, the Netherlands, respectively

Aphidius rhopalosiphi produced 212 offspring on average but in one case 509 deposited eggs were found. Superparasitization occurred but the frequency distribution of parastoid lascrimination. Avere life spen of adrom random, indicating a certain degree of was $1: 1$. I

Handling time was about $2 \mathrm{sec}$ and was soruewhat longer in the fourth instar than in the
second. Second and third aphid instars were preferred for oviposition. Functional response was sigmoid and at an aphid density of 100 aphids per cage percentage parasitiza-
tion decreased.

KEY wORDS: Hymenoptera - Aphidiidae Aphidius rhopalosiphi - Sitobion avenae -

Several aphid species attack cereals in Western Europe but Sitobion avenae F. and Metopolo phium dirhodum Wlk. are the dominant one Both species are attacked by a large number of predator and parasitoid species but relatively little is known of their bionomics. It has been suggested, however, that these enemies exert significant delaying effect on aphid population development (Edwards et al. 1979; Jones, 1972; Rautapää, 1972, 1975). The lack of information concerning natural enemies has also caused problems in developing simulation models to predict aphid population build-up with a view to forecasting outbreaks.

An intensive laboratory study was undertaken on one parasitoid species, Aphidius rhopalosiphi De Stephanie-Perez, with S. avenae as the host, to provide information to assess it importance in aphid population and for use in simulation models.

Although the species composition of parasitoids changes from year to year, A. rhopalos phi is ustally one of the commonest species (McLean, 1980) in Western Europe. The stud

3,4) Present addresses: Laboratory of Entomology,
Faculty of Agriculture, Hirosaki University, HiFaculty of Agriculture, Hirosaki University, Hi-
rosaki, Aomori 036, Japan, and the Game Conresaki, Aomori 036, Japan, and the Game ConEngland, respectively looked at several aspects of the adult female

TERIALS AND METHODS

Standardization of adult parasitoids. The biology of a parasitoid depends on many factors initial number of egos in the ovaries, etc - so all the experiments were carried out with standardized parasitoids. They were cultured in the following way: groups of two to three adult aphids (green colour form) (from a greenhouse mass culture, kept at approx. $18^{\circ}, 70 \%$ r.h. and $18 \mathrm{hr}$ light) were placed in small plastic cages $(3 \times 3 \times 10 \mathrm{~cm})$ each enclosing one winter wheat seedling lea (cv. Arminda), for 2-3 days in a constant temperature room (used in all the experiments to follow - kept at $18^{\circ}, 75 \%$ r.h. and $18 \mathrm{hr}$ light). After this period the adult aphids were removed and one female and one or two male parasider the same conditions as the aphid culture) were introduced into a cage for 24 hr. After 10-12 days, any mummies (parasitized aphids) which had been produced were' put separately, into either glass tubes $(1.5 \mathrm{~cm}$ diameter and $5.0 \mathrm{~cm}$ high) or small gelatine mummies were checked daily until the parasitoids history. Thus parasito ids of known age bers for the experiments.

Fecundity, longevity and sex ratio. Forty 2-3 parasitoids biology; fecundity, longevity, hos toids (also from a greenhouse culture kept uncapsules, together with a piece of leaf. These 
day old aphids (first to second instar) were
placed on a seedling (fifth leaf stage, each leaf placed on a seedling (fifth leaf stage, each leaf in a cylindrical plastic wide by $10.0 \mathrm{~cm}$ long) in a cylindrical plastic cage $(11 \mathrm{~cm}$ diameter
and $62 \mathrm{~cm}$ high, with six circular gauze windows, $8 \mathrm{~cm}$ diameter) and then left for at least one day.

Then one mated female parasitoid was introduced into the cage. After $24 \mathrm{hr}$ the parasitoid was transferred to a fresh seedling in another cage, also with 40 aphids. This process was repeated daily until the parasitoid died. The parasitoids were fed with honey on glass slides placed in the cages every day. In total 17 specimens (six newly emerged, three 1 day old, four 2 days old and four 3 days old females) were used in these tests. At least 10 of the 40 aphids were dissected 5 days after parasitization to determine the degree of superparasitization. Realized fecundity was determined by adding to the number of mummies found per parasitoid, the numbers of dissected aphids with at
least one larva of the parasitoid. All the hosts from one replicate were dissected to find the total number of eggs laid by that parasitoid.
Longevity and sex ratio (of the adults emerging from the mummies) could also be determined.

To obtain an estimate of the potential fecundity, 18 standardized parasitoids were disaying to count the initial number of eggs present in the ovaries. Host selection and handling time. Prior to the the parasitoids went through a procedure to gain experience in handling aphids. On the day of emergence $q$ parasitoids were mated with $\delta \delta^{t}$ and then left for $2-3 \mathrm{hr}$ with a mixture of aphid instars in a small glass tube. The $q$ parasitoids were then left overnight with no aphids but were fed with honey and water (Van Lenteren, 1976). As these parasitoids had been deprived of hosts they quickly started searching
for aphids when they were introduced into the experimental arena.

The parasitoids were given a choice between 2-3 day old (second instar) and 7-8 day old (fourth instar) aphids or $1-2$ day old (first instar) and 5-6 day old (third instar) aphids. Ten aphids from each instar were weighed be fore each experiment. Four nymphs of each instar to be tested were placed onto eight seed-
ling leaves stuck to the bottom of a glass Petri

dish (18.6 $\mathrm{cm}$ in diameter). This was placed 25 $\mathrm{cm}$ over a light-box in a blacked-out cubicle. This design encouraged the parasitoids to search on the bottom of the dish as they are attled the parasitoid was introduced and the moment it started searching was noted. Every encounter, a clearly visible contact of the parasitoid's antennae with an aphid, was timed, classified by instar and noted, together with information on whether the parasitoid appeared to oviposit or not. If an aphid was attacked it was replaced with a similar aphid, thus keeping the aphid density and instar composition constant. When ten aphids of the least favoured instar had been attacked the observations were stopped, the time noted and the parasitoid removed and weighed. The aphids the reared for 5-6 days and then dissed to determine the proportion parasitized.

Functional response. The functional response of the parasitoid was investigated using host densities of $5,10,20,40$ and 100 (2-3 day old and plastic cylindrical cares similar to those used in the fecundity experiment. The aphids were carefully tranferred to the leaves of the plant and allowed to settle. One day after, one mated female parasitoid (2-5 days old) was introduced and left with its hosts for $24 \mathrm{hr}$ and then removed. The aphids were then reared on the plant until mummification. After 12 days any mummies which had been. After 12 days any mummies which had been produced were ties $5,10,20,40$ and 100 were $50,40,20,57$ and 10 respectively.

\section{RESULTS}

Fecundity, longevity and sex ratio. The potential fecundity (number of eggs in the ovaries found by dissecting 18 parasitoids) was $144.3 \pm 17.8$ (mean \pm s.e.) which is significantly less than the realized fecundity of $212.4 \pm 69$ found in 14 parasitoids (Table I) $(\mathrm{t}=3.99, \mathrm{P}<0.001$, d.f. $=30)$. Eggs were therefore still being matured during adult life. Egg laying was most intensive during the first week or so of adult life but then declined rapidly such that it had all but stopped by the end of the second week (Fig. 1). The results of the parasitoid experiment, where all the aphids were dissected, indicate that 1.5 times the mummies suggested, which means a realized aphid density (five) the average number of mummies produced was 1.7 (33\% parasitization). Up to and including the aphid density of 20 the percentage parasitization declined while the-number of -mummies-produced increased est percentage parasitism of $64 \%$ was recorded at aphid density 40 . At the highest aphid density (100) the average number of mummies produced was 46.7 but this represents a reduction in the percentage parasitization probably due to egg limitation (see fecundity experiment), or perhaps because disturbance from the parasitoid caused many of the aphids to drop from
the plant which resulted in a low parasitization rate.

DISCUSSION

A. rhopalosiphi showed the typical characteristics of the genus: high fecundity (a realized fecundity of 212), mode dling time (about $2 \mathrm{sec}$ ). Other species which have been studied include $A$ ervi (Starý, 1962), A matricariae ('t Hart et al., 1978), A. smithi (Wiackowski, 1962; Mackauer \& van den Bosch, 1973), and A uzbekistanicus den Bosch, 1973), and A. uzbekistanicus (Starý, 1972; Dransfield, 1979). Although their hosts with their antennae and then oviposit very quickly. The ability to discriminate between parasitized and unparasitized hosts is present ('t Hart et al., 1978), although Starý (1962) states superparasitism does take place but this might be due to the experimental setup. Aphidius spp., in general, attack the younger instars, especially second and third instar. 't Hart et al. (1978), although finding no clear preference with A. matricariae, concluded that it would be preferable (for biological control) for Aphidius to parasitize small larvae because (1) the percentage of eggs re-
sulting in adult parasitoids is higher if oviposisulting in adult parasitoids is higher if oviposition takes place in small larvae rather than in large larvae; (2) it takes less time to parasitize small than large larvae although this is likely to be unimportant as the time taken to parasitize large aphids is still short; (3) kicking of the aphids, especially the 4th instar larvae an adult aphids frightens the parasitoids.

The first reason is important to the survival

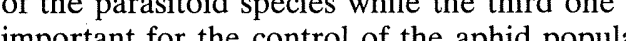
tion. It is the cor tho scription whether the lower percentage of adult parasitoids emerging from larger aphids is a result of lower larval parasitoid survival or study a lower egg laying rate. In the present the latter was more likely unless the morval stage.

Dransfield (1979) demonstrated that $A$. $u z$ bekistanicus has a type 2 functional response when confined in a small cage $\left(1656 \mathrm{~cm}^{3}\right)$ for hr. Van Lenteren \& Bakker (1976) have shown that this experimental procedure invariably leads to a type 2 response because the parasitoid is prevented from leaving the cage. This results in repeated searches of the host location and eventually in the parasitization of nearly all the hosts. In the present study larger cage $\left(5890 \mathrm{~cm}^{3}\right)$ was used and this proband hence the type 3 rosponse was (1977) imply that inertebrate predators and parasitoids have type 3 responses caused by changes in the instantaneous attack rate ' $a$ '. As prey or host density increases then ' $\mathrm{a}$ ' increases and when this is incorporated in mathematical models sigmoid reponses are generated. Verification of this relationship is however very difficult.

The biological characteristics of $A$. rhopalo siphi make it potentially an important regulating factor in cereal aphid population dynamics. Unfortunately, parasitoids are themselves parsitized by several hyperparasitoid species and hese can be very numerous (Carter et al., 1980; Rabbinge et al., 1979). Indeed, Jones (1972) has argued that the aphid-parasitoid-hyperparasitoid interaction causes cyclic outbreaks of cereal aphids about once every ears. Although this interaction may be important it is unlikely to be the only factor influencing aphid outbreaks as during the late 1970 ' outbreaks occurred in $1975,1976,1977$ and 979 (Rabbinge et al., 1979; Carter et al., 980)

The authors thank Ir. P. Dentener and Mr. H. Dijkman for help with experiments, Dr. J. d Wre, Dr. C. de Wit a Ms. Sara ing and B. H. Jan Amersfort for ty. $\mathrm{N}$. Carter was finonced by Fellowship from the Royal Society/SRC/NATO and Dr. Y. Shirota by a grant from the In. gen. 
handling times being about 2 sec. Apparently this short handling time is not a limiting factor very short and the exceptional cases with longer handling times have a considerable effect the encounter rate and the number of resulting

aphid instars one and three is not significant $(\mathrm{t}=0.78$, d.f. $=6$, N.S.; $\mathrm{T}=10$, N.S.) but with instars two and four it is $(t=3.35$, very short. Paired 2 sec, which is nevertheless larvae/encounter were combined, an overall signed-rank test show no significant difference suphids this was $0.08 \pm 0.02$ For first instar between handling times of the parasitoid with $0.12 \pm 0.02$ whird instar $0.15 \pm 0.04$ and for first and third instar aphids ( $\mathrm{t}=0.04, \mathrm{n}=14$ fourth instar $0.07 \pm 0.02$. N.S.: $T=48.5$, N.S.) but a significant differ- which suts ence between handling times with second and red" to lay egos in fourth instar aphids $(t=2.97, p=0.01$ aphids but there is no significant difference be $\mathrm{n}=15 ; \mathrm{T}=11.5, \mathrm{P}<0.01, \mathrm{n}=14)$. It also tween either pair of results. It is probable be$\mathrm{n}=15, \mathrm{P}=11.5, \mathrm{P}<0.01, \mathrm{n}=14)$. It also tween either pair of results. It is probable also pecially kicking with the back legs, with the vae of the parasitoid did not survive to be relater instars, while the parasitoid had problems corded. Hence what was being measured was a combination of the egg laying success and sur-

Aphid weight affected the proportion of successful encounters, which were high for the first three instars but dropped for the fourth Functional response. The shape of the parasi(Fig. 4b). The difference between the number toid's functional response curve is the sigmoid of resulting parasitoid larvae/encounter with type 3 (Holling, 1959) (Fig. 5). At the lowest

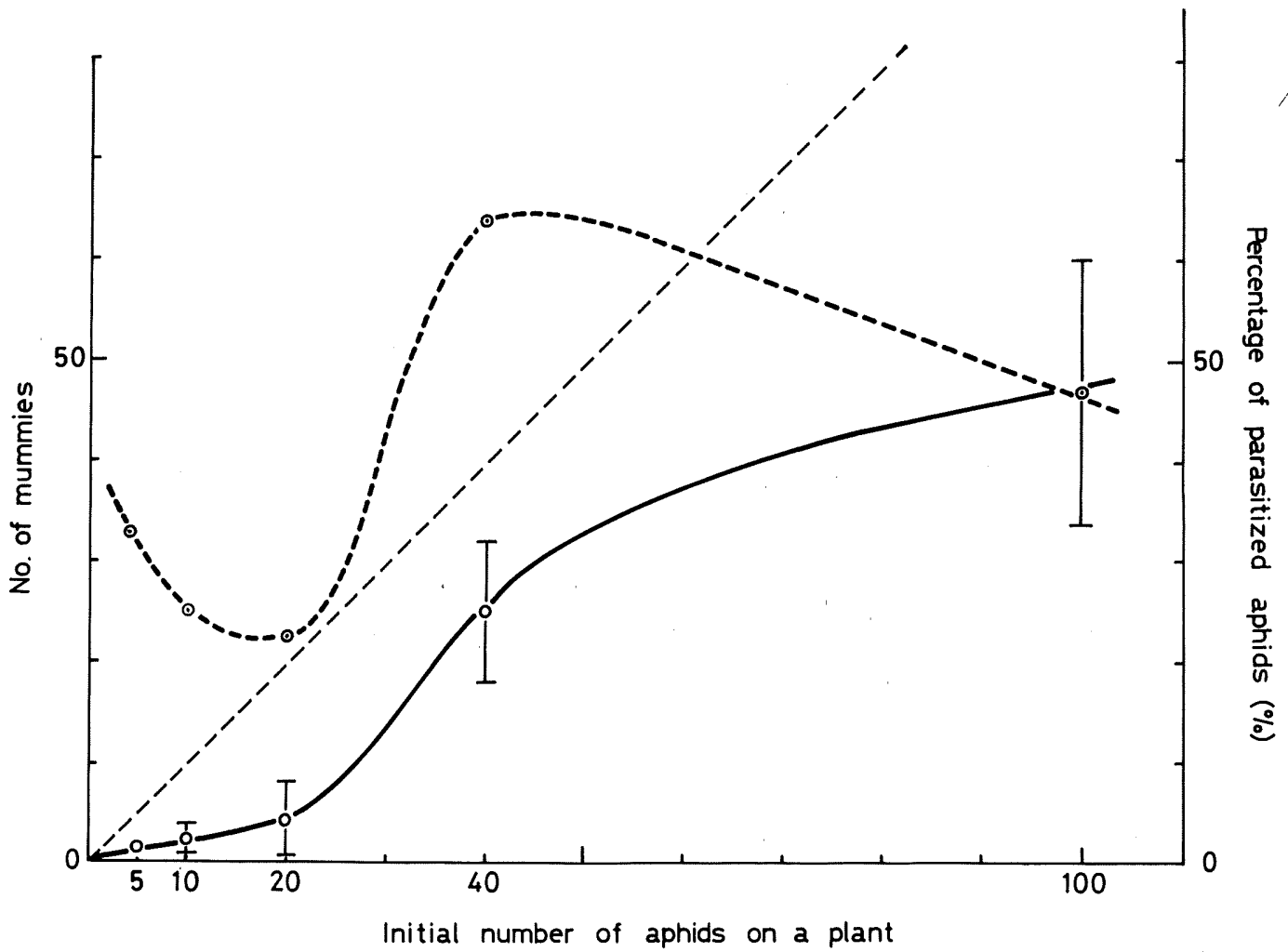

Initial number of aphide

Fig. 5. The functional response of $A$. rhopalosiphi (solid line) and percentage of parasitized aphids (broken line) to changes in host density.

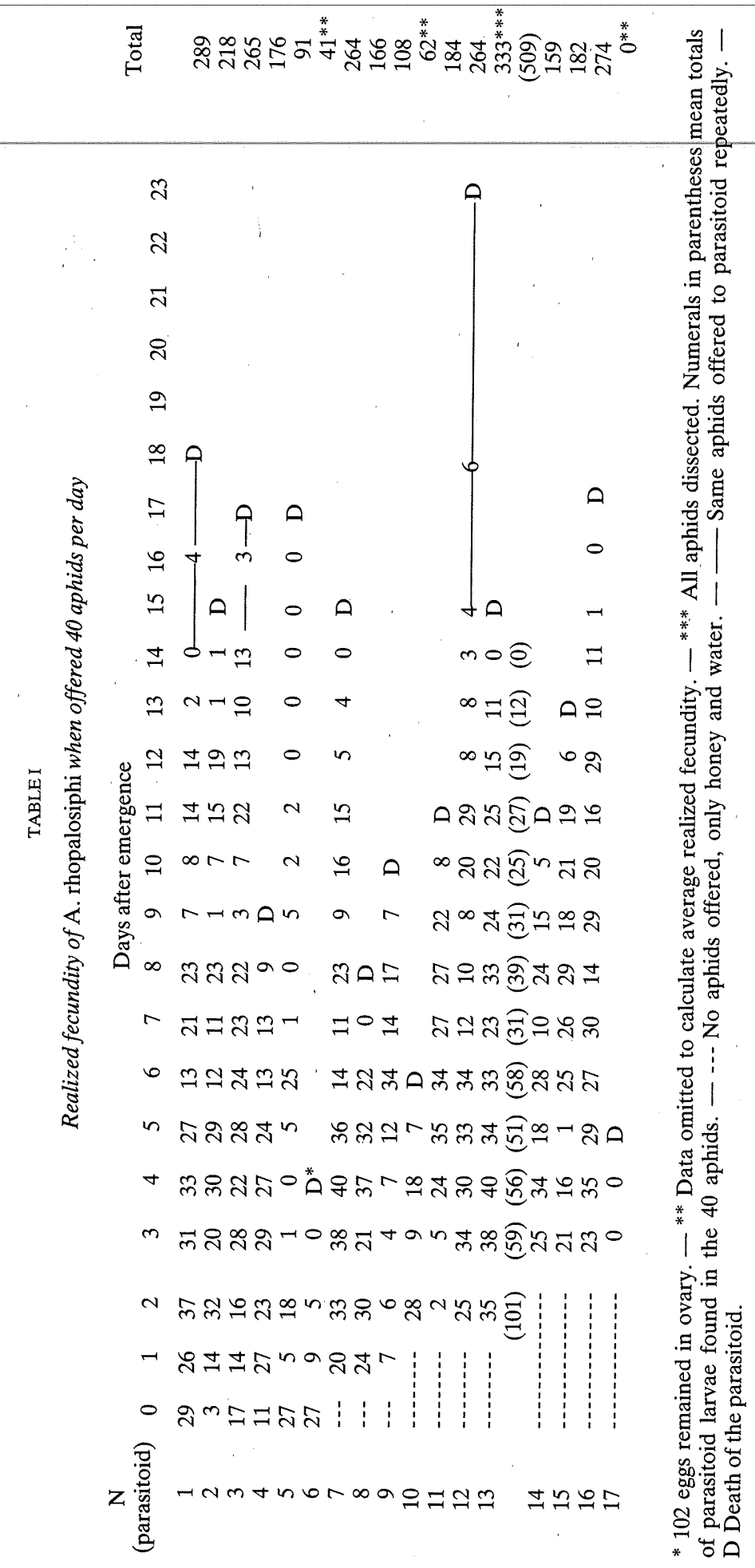




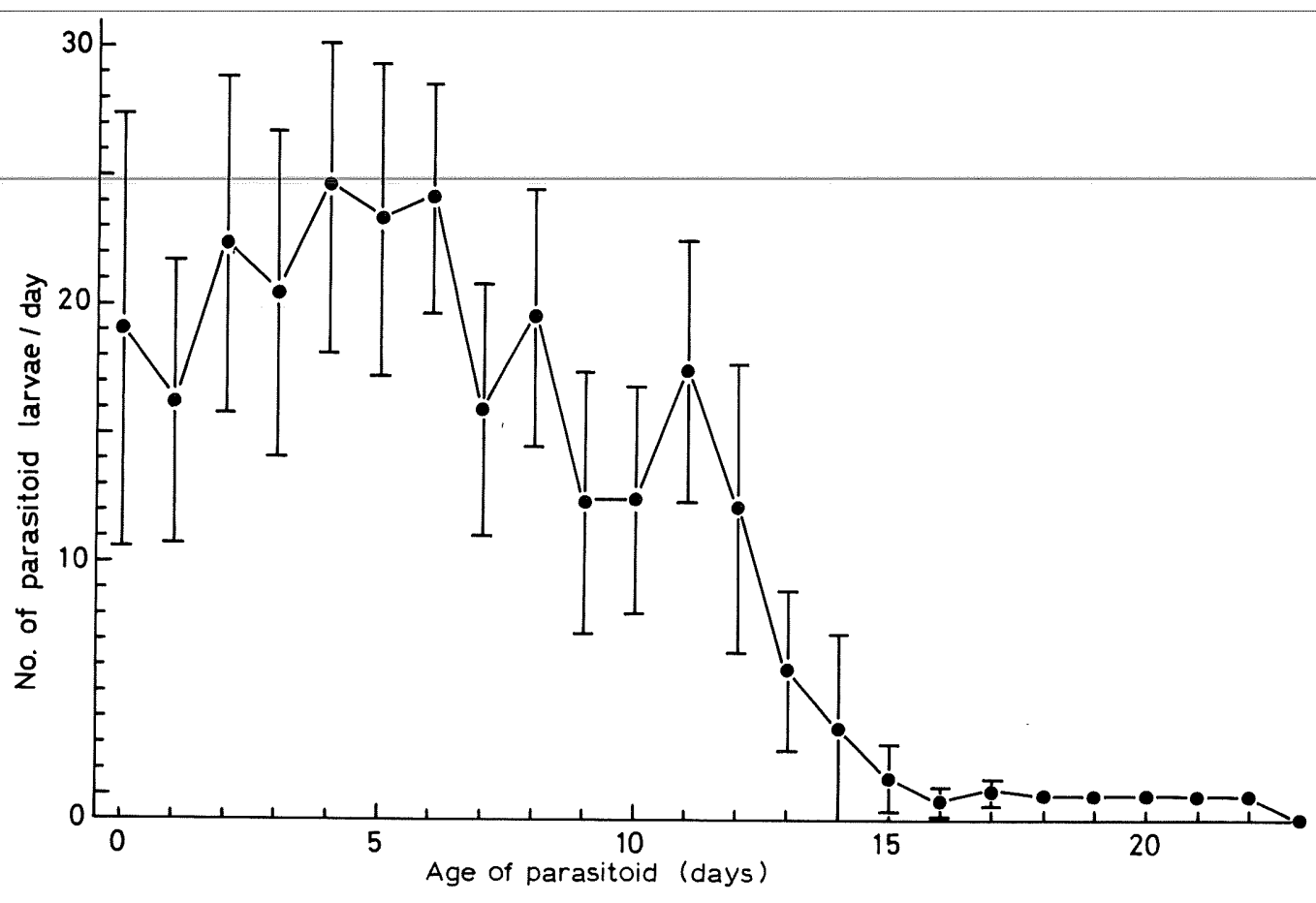

Fig. 1. Daily realized reproduction of $A$. rhopalosiph $i$ with 40 aphid nymphs as hosts $(\alpha=0.05$ Con. Int.)

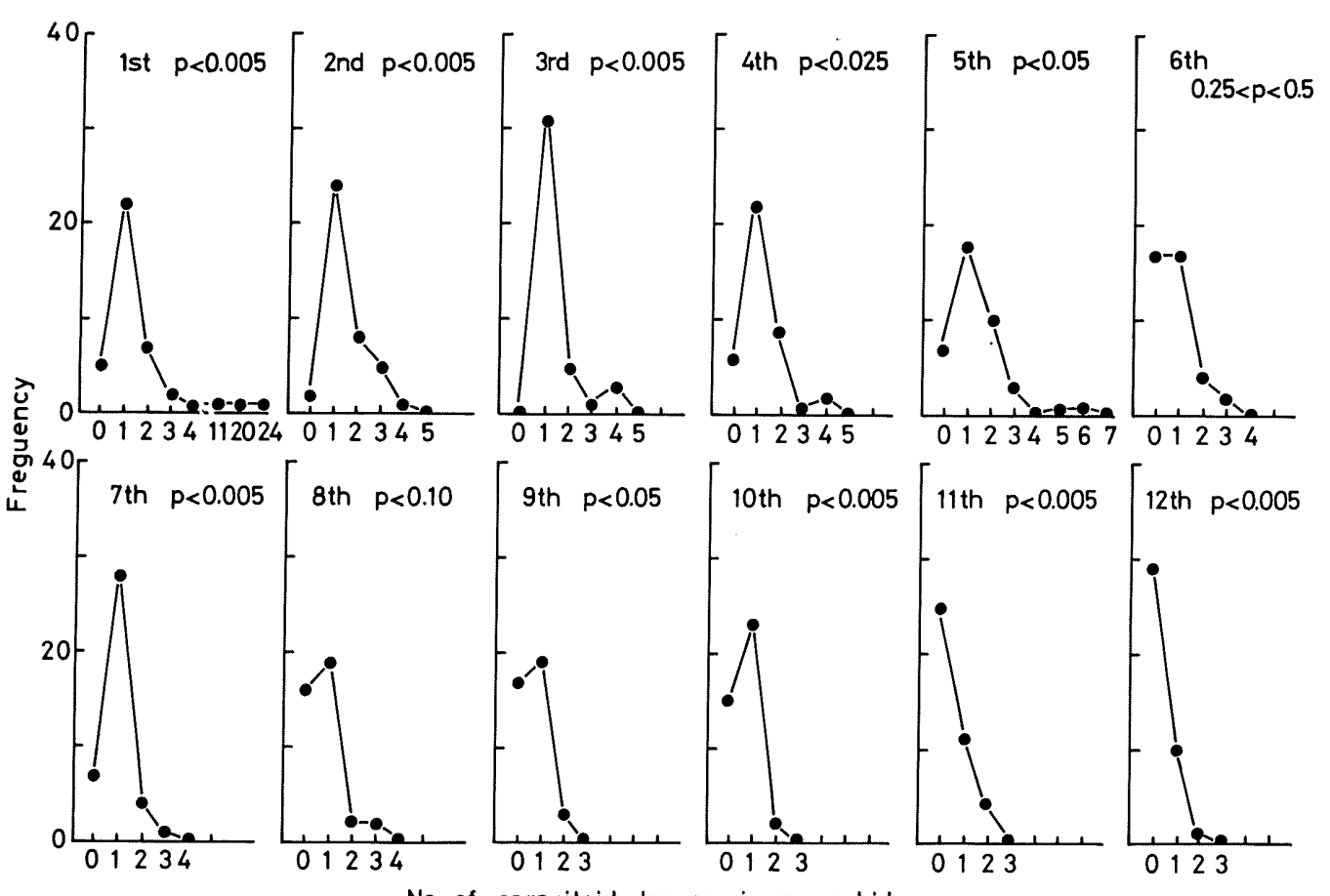

Fig. 2. Frequency distribution of larvae of $A$. rhopalosiphi in aphids.

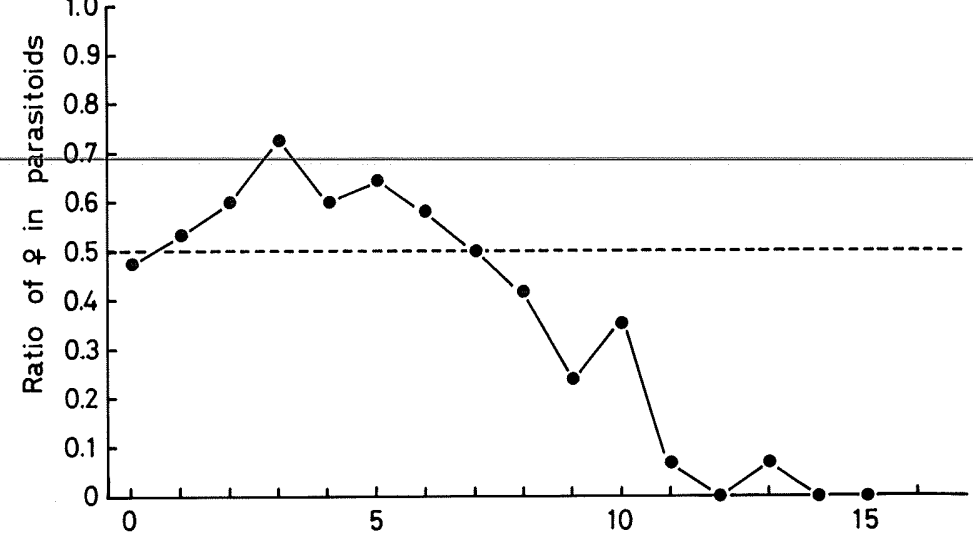

Age of parasitoid (days)

Fig. 3. Sex ratio of emerging A. rhopalosiphi as a

greater) as the parasitoid had problems in at-

fecundity of about 318 and not 212. Hence superparasitism occurred in this species under these experimental conditions. However, the frequency distribution of parasitoid larvae in aphids (Fig. 2) shows a significant difference $\left(\chi^{2}\right.$-test) from a random distribution on the 1 st, 2nd, 3rd, 4th, 5th, 7th, 9th and 10th day. This is due to the observed high frequency of aphids that the parasitoid had a partial tendency to avoid superparasitism.

The maximum longevity was 23 days while the average was $13.1 \pm 1.3$. Thus the average life span corresponded to the period of reproduction - i.e. the post-reproductive period was very short. The sex ratio shows a consistent trend among all the parasitoids tested (Fig. 3). For the first day the ratio was almost $1: 1$ but after this the proportion of $q q$ was higher up to 6 days atter emergence, after more. The sex ratio of total offspring was $1: 1$.

Host selection and handling time. The encounter rate of aphids the size (or age) of the aphid (Fig. 4a) - the larger the aphid the more frequently it was encountered - but not on the size of the parasitoid. The parasitoid took $1.6 \pm 0.2 \mathrm{sec}$ to handle second instar aphids but $2 \mathrm{sec}$ or more to handle the other three nymphal instars $(2.1 \pm 0.3,2.0 \pm 0.2$ and $2.3 \pm 0.2 \mathrm{sec}$ respectively). The distribution of handling times is skewed to the left because most encounters lasted for $1 \mathrm{sec}$ or less but on several occasions longer handling times occurred (10 sec or tacking the aphid. This resulted in the mean

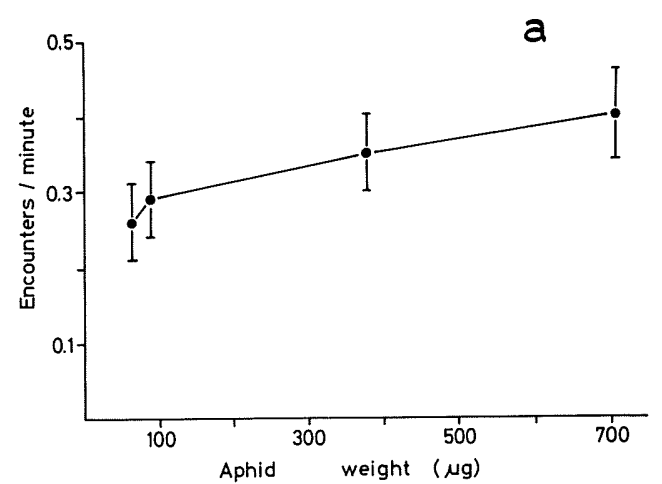

b

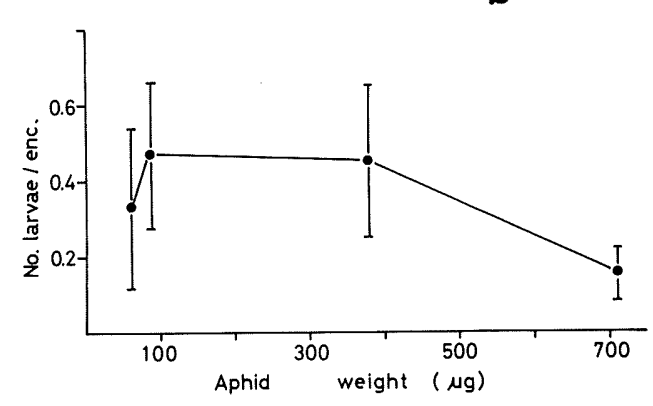

Fig. 4. (a) The effect of aphid weight on the encounter rate of A. rhopalosiphi. (b) The effect of aphid weight on the proportion of successful encounters of A. rhopalosiphi ( $\alpha=0.05$ Con. Int.). 